\title{
Las nuevas tecnologías de la información y el futuro de la Documentación
}

\author{
Francisco Javier García Marco \\ Universidad de Zaragoza \\ E-mail: jgarcia@posta.unizar.es
}

Las denominadas 'nuevas tecnologías de la información' son reconocidas como una parte fundamental del currículum formativo de los profesionales de la información y la documentación. Lo son tanto en los planes de estudio oficiales como en las recomendaciones de las asociaciones profesionales.

Durante muchos años, sin embargo, la educación en nuevas tecnologías de la información quedó encapsulada en programas de formación específicos, sin invadir el resto de las asignaturas y especializaciones profesionales. Constituían un necesario complemento, ineludible ciertamente y, muy ligado a la formación en Ofimática básica, en aplicaciones de comunicación y en el desarrollo y consulta de bases de datos. En seguida se detectó también la importancia de proporcionar formación para la publicación de información en la Internet y proliferaron los cursos de edición de páginas web. Pero siempre la formación en tecnologías informáticas podía aislarse de las demás áreas del curriculum-gestión, catalogación, teoría e historia de las Ciencias de la Documentación, etc. - como algo diferente.

Los artículos que presentamos en este número muestran hasta que punto la situación ha cambiado en los cinco últimos años. La informática y las tecnologías de la comunicación han penetrado — mejor diríamos, invadido- las Ciencias de la Documentación: su concepto, sus modelos y teorías, y todas y cada una de las fases de la cadena documental. Este hecho queda patente en los trabajos que presentamos al lector en este nuevo número de Scire.

La lección más importante que obtenemos de los trabajos de nuestros compañeros y amigos es que las nuevas tecnologías de la información ya no son sólo 
una materia de estudio ineludible, sino la plataforma tecnológica sobre la que se desarrolla nuestro trabajo, y de la que ya no podremos separarlo nunca.

Por más que nos encontremos en una fase de transición, es evidente que la hegemonía del papel y el celuloide ha dejado paso a la tecnología de la información digital.

No es extraño, por tanto, que la necesidad y la pasión por lo tecnológico haya invadido nuestro trabajo profesional y académico. Por suerte, y a diferencia de lo que nos pasaba hace pocos años, la Red es algo que se da ya por supuesto. En la medida en que ha dejado de ser un horizonte lejano que conquistar, podemos sentirnos ya libres para volver nuestra atención sobre las preguntas fundamentales, que, no es extraño tampoco, son las preguntas de siempre.

En este sentido, debemos agradecer al destacado investigador inglés Alan Gilchrist que comparta con nosotros su excelente reflexión sobre el impacto de las nuevas tecnologías de la información, descubriéndonos sin complejos ni juegos sus preocupaciones y reflexiones. De forma incisiva y provocadora, plantea la tesis de su trabajo ya en el título: "Las tecnologías serían la respuesta, si conocieramos las preguntas".

Efectivamente, el sentido común nos muestra que la herramienta es sólo eso, un instrumento al servicio de un fin. También reconocemos normalmente que la determinación de los fines es lo que caracteriza al ser humano, capaz de construir esos conceptos extraordinarios que llamamos valores, que guían nuestras vidas y nos permiten cohesionarnos en proyectos sociales.

Sin embargo, la pregunta no sobra: ¿Estamos confundiendo las herramientas con fines? ¿Profundizamos en los fines y los perseguimos con la misma energía que dedicamos a las herramientas? Muchos hechos que suceden en nuestro entorno indican que debemos responder sí a la primera pregunta y no a la segunda.

Ciertamente, la Red no es sólo la infraestructura comunicacional de nuestra sociedad, es mucho más y merece toda nuestra atención. El mundo de la realidad virtual es un universo nuevo que acaba de estallar en un auténtico Big Ban. Como profesionales y académicos de la información y la documentación, contemplamos, atónitos, el surgimiento de un Nuevo Mundo, un mundo construido sólo de información, una América apasionante llena de promesas de futuro, de ilusión y de bienestar.

Pero, ¿cuidado!, andemos con un ojo en el horizonte que perseguimos (los fines) y otro en los pasos que damos (la metodología) y releamos de vez en cuando la Parábola de los tres hermanos que tan estupendamente trova el cantautor cubano Silvio Rodríguez. Ánimo a todos y saludos cordiales.

Zaragoza, a 30 de diciembre de 1998.

Scire. 4 : 1 (en.-jun. 1998) 9-10. 